\title{
An Integrated Forecasting DSS Architecture in Supply Chain Management
}

\author{
Tien-You Wang \\ Department of International Business Management, Tainan University of Technology, Taiwan R.O.C. \\ E-mail:prisca@seed.net.tw \\ Din-Horng Yeh \\ Department of Business Administration, National Chung Cheng University, Taiwan R.O.C. \\ E-mail: bmadhy@ccu.edu.tw
}

\begin{abstract}
In a competing market environment, supply chain management (SCM) has been critical for companies to survive. Demand planning plays an important role in SCM, for it provides accurate demand forecasts which may achieve customer satisfaction by offering benefits such as low inventory level, short lead time, efficient resource allocation, and quick response. To obtain more accurate forecasts, this study presents a web-based DSS architecture and its forecasting core. The forecasting core, named Panel Function, contains three modules: Segmentation Module, Forecasting Module, and Coordination Module. Segmentation Module employs data mining technology to categorize customers with different characteristics into three segments: Loyal Customer Segment, Potential Customer Segment, and Switcher Segment. Based on the three segments, Forecasting Module employs different forecasting and analysis technologies to estimate an integrated forecast: time-series forecasting to capture the loyal customer demand trend, Bayesian inference to estimate the predicted value of switcher purchase quantity, and questionnaire analysis and brand choice models to unearth potential customers. An integration function then synthesizes the results from these three processes to obtain the integrated forecast. Coordination Module then takes this integrated forecast as the base of distribution planning, and provides a minimal system-wide total cost solution for all parties in the supply chain. As a whole, this DSS architecture is anticipated to provide an efficient mechanism for collaborative demand planning, and help create the maximum profit for the supply chain.
\end{abstract}

Keywords: Web-based DSS, forecasting, purchase tendency, integrated forecast, data mining

\section{Introduction}

Supply chain management (SCM), a hot business issue for the past decade, has been granted as the solution of survival in current competing market environment. Many companies recognize the importance of SCM in order to remain competitive; however, the implementation of SCM seems no easy task to be accomplished. According to a Deloitte Consulting survey in 1998, about $91 \%$ of North American manufacturers rank SCM as very important or critical to their company's success; however, only $2 \%$ of them rank their supply chains as world class (Thomas, 1999).
The main reason for this extreme disparity might be the complexity of integrating logistics operations and various information technologies among firms (Patterson, Grimm, \& Corsi, 2003). Many researches point out that firms were confronted with various obstacles of employing SCM, including communication and coordination among different suppliers (Fredenhall \& Hill, 2001), high costs of the implementation of EDI (Machuca \& Barajas, 2004), investment in employing information systems and developing information technology (IT) skills of their employees (Gunasekaran \& Ngai, 2004), the complex relationships in a supply chain, etc. 
The participants in a supply chain form an alliance that can quickly bring together a set of core competencies to take advantage of market opportunities. This leads to the advantages such as adaptability, flexibility, agility, ability to globalize, and also allows partner firms to concentrate on their core competence (Strader, Lin, \& Shaw, 1998). The alliance requires timely availability of information throughout the supply chain to allow cooperative and synchronized flow of material, products, and information among all participants (Ghiassi \& Spera, 2003). However, exhaustive collaboration is required in such an environment, and firm managers are often reluctant to devote themselves to a virtual team because they might lose control of proprietary information and technology. Meanwhile, managers also have to trust outsiders and do much more negotiation and coordination (Strader et al., 1998). All the above difficulties in SCM may possibly account for the phenomenon of the well-known bullwhip effect.

The bullwhip effect happens when the demand information moving upstream in a supply chain is distorted and amplified. Lee et al. (1997) identified one of the main causes was demand forecast updating. They contended that demand signal processing (implicating information delays) was a major contributor to the bullwhip effect. The amplified demand forecasts induce serious inventory problems. Lee et al. (1997) also pointed out that one remedy was to make demand data at downstream sites available to the upstream sites, so that both sites could update their forecasts with the same raw data. Explanation of this remedy is as depicted in Figure 1. Strader et al. (1998) presented an information infrastructure for a firm and its partners in a virtual organization, and the infrastructure may also show information relationships among the members in a supply chain. As shown in Figure 1, retailers make forecasts on customer demand, and replenish their inventory according to the forecasts; then, manufacturers collect orders from different retailers, and order the material from their suppliers. All these activities proceed in the information environment with Webbased Decision Support System (DSS) application tools.

The question is: even though the demand data are shared with both upstream and downstream sites, the inaccurate forecasts led by limitations of current forecasting technologies still remain as a major problem of inventory in SCM. Demand forecasting may play an important role to minimize the bullwhip effect in SCM, because accurate demand forecasts may achieve customer satisfaction by offering benefits such as lower inventory level, shorter lead time, efficient resource allocation, and quick response. However, the performance of

Figure 1 Web-based Architecture for Demand Planning

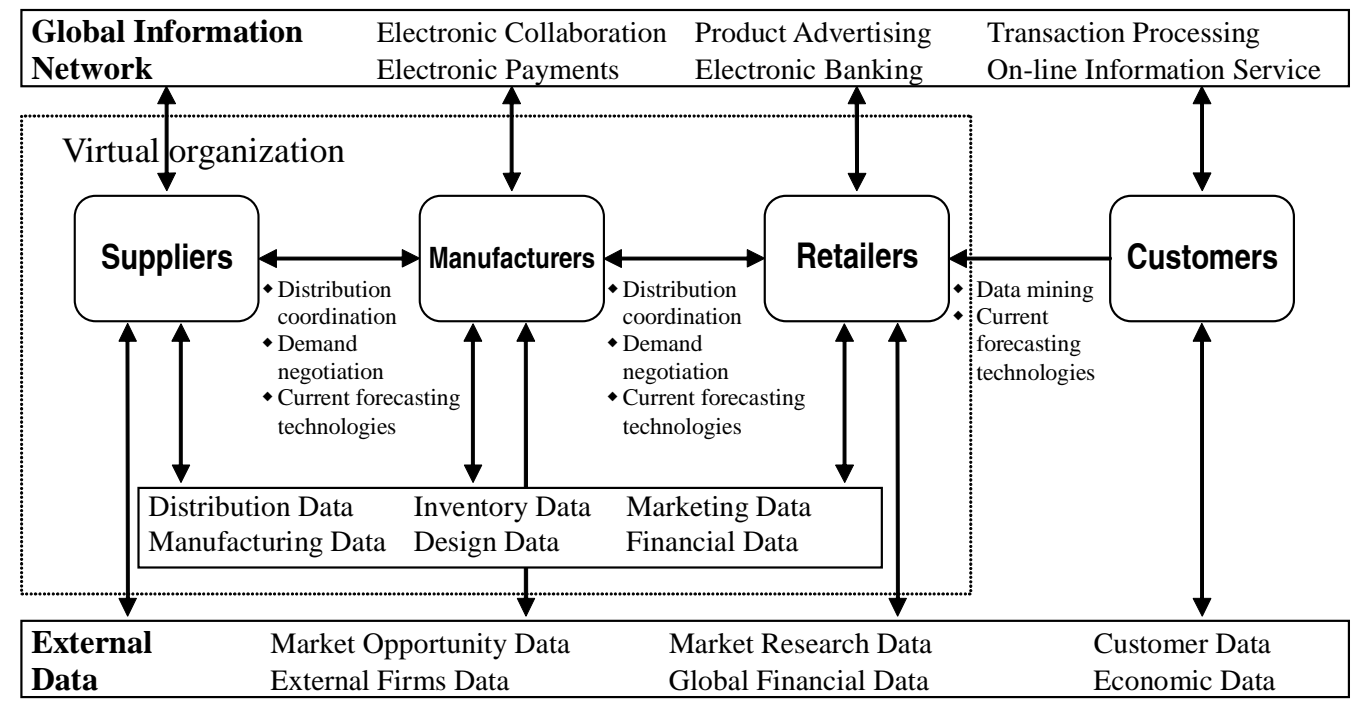

* Modified from Strader et al., 1998. 
demand forecasting has been staggering due to the changing market environment and the limitation of existing forecasting technologies.

This study attempts to improve forecasting performance, and to facilitate collaborative forecasting in a supply chain, by presenting a webbased DSS architecture with an integrated forecasting core. The integrated forecasting core focuses on the retailer end, and it separates customers into different segments according to customer purchase behavior. The diversity of customer purchase behavior contributes to the demand pattern variation significantly in retailing industry, so customer purchase tendency is selected for exploring a forecasting alternative that is distinguished from traditional time-series technologies. From the point of view of resource allocation, retail management should prioritize customers in the following order: (1) existing loyal customers, (2) new entrants to the market, and (3) shoppers who are potentially switchable from competitors (Rhee \& Bell, 2002). Based on this viewpoint, customers are classified into three segments in the integrated forecasting core: Loyal Customer Segment, Switcher Segment, and Potential Customer Segment; different technologies are then employed in each segment in accordance with their characteristics. Definition of each customer segment is described as follows. The term "Loyal Customer" stands for the customers who purchase the specific product constantly, "Switcher" refers to those who purchase only at premium prices, and "Potential Customer" represents those who have never purchased that product but might be with high possibility of purchasing in the future.

In the integrated forecasting core, we first employ appropriate forecasting methods to predict the demand of each customer segment according to their behavior; then an integration function is used to take the results from each customer segment to obtain the integrated forecast, which is anticipated to attenuate the forecasting error. The detailed description of the proposed architecture is given in the following sections: Section 2 illustrates these technologies and related researches, followed in Section 3 by the description of the presented Webbased DSS architecture; Section 4 describes the forecasting core, and discussion of the implication of this architecture is given in Section 5; and Section 6 draws the conclusion and future research.

\section{Applications of Related Technologies}

The technologies involved in the presented DSS architecture consist of different domains, including decision support system, data mining, time-series forecasting, Bayesian inference, and brand choice models. This section is devoted to illustrate these technologies and some of their applications as follows.

\subsection{Decision Support System (DSS)}

DSS technology has been rising and flourishing since 1970s. Classic DSS is comprised of components for sophisticated database management ability, powerful modeling functions, and simple user interface that enable interactive queries, reporting, and graphing functions (Shim et al., 2002), the design of DSS involves helping decision-makers face with semistructured and unstructured problems.

Shim et al. (2002) presented the evolution and categories of DSS, including data warehousing, OnLine Analytical Processing (OLAP), data mining, Web-based DSS, collaborative support systems, and optimization-based DSS. A Web-based DSS refers to a computerized system that delivers decision support information through a web browser to someone who needs it. When a user sends requests on a website, this system passes the requests to a database server which generates the query result set and sends it back for viewing. A Web-based DSS serves incessantly with data warehouses and OLAP, but web database architecture should be able to handle a large number of concurrent requests when the number of users increases. The web environment is emerging as a very important platform for DSS development, using a web infrastructure for building DSS improves the rapid dissemination of decision-making frameworks and promotes more consistent decision making on repetitive tasks. This may help facilitate collaboration between the supply chain members, so Web-based DSS is chosen as the DSS architecture in this study.

Bhargava, Power, \& Sun (2007) provided their review on Web-based DSS, and summarized five types of Web-based DSS: data-driven, model-driven, communication-driven, knowledge- driven, and document-driven DSS. Data-driven DSS help managers organize, retrieve, and analyze large 
volumes of relevant data using database queries and OLAP techniques. Model-driven DSS use formal representations of decision models and provide analytical support using the tools of decision analysis, optimization, stochastic modeling, simulation, statistics, and logic modeling (Bhargava et al., 2007). These two types are the most widely implemented approaches for delivering decision support, some articles referring to decision support modeling in supply chain management reinforce this summary (Biswas \& Narahari, 2004; Blackhurst, Wu, \& O'Grady, 2005; Min \& Zhou, 2002; RÃ̃̃der \& Tibken, 2006).

In practice, supply chain members may carry out their group forecasting process via a Web-based DSS with two different strategies: Collaborative Planning, Forecasting, and Replenishment (CPFR) or Vendor Managed Inventory (VMI). With CPFR strategy, vendors develop their business plans jointly with retailers. Public guidelines have been established to prescribe methods to implement the CPFR process. Fore instance, the Voluntary Interindustry Commerce Standards (VICS) committed, a group dedicated to the adoption of bar-coding and EDI in department store/mass merchandize industries, has developed a nine-step process model as a guideline for CPFR implementation, which is drawn in Figure 2 (VICS, 2000; Barratt \& Oliveira, 2001; Seifert, 2003; Crum \& Palmatier, 2004; Danese, Romanob, \& Vinelli, 2004).

Some CPFR portals are developed for collaboration in the supply chain; a typical example is the e-supply chain portal constructed by U.S. Department of Defense for F101. This portal contains available tools for supply chain members, including key performance indicators, geographic information, decision support, sensor data, and collaborative tools such as on-line forecast. Supply chain members may use collaborative forecasting via these tools to attenuate the risk of bullwhip effect (Boyson, Corsi, \& Verbraeck, 2003). Figure 3 shows the forecast function in the e-supply chain portal.

With VMI strategy, under a VMI agreement, the retailers use the Web-based DSS to provide seasonal promotional plans and sales data to the vendor, the vendor produces sales forecasts and supply the inventory to meet agreed upon customer service levels and inventory turnover targets (Achabal, Mcintyre, Smith, \& Kalyanam, 2000). Figure 4 shows an overview of the models for VMI system.

These two strategies involve the decision mechanism between retailers and vendors in a supply chain, not the forecasting technology. The Web-based DSS architecture proposed in this paper goes further on discussing an integrated forecasting technology. The forecasting core in the architecture integrates the forecasts from different customer segments, including potential customer segment, to explore better forecasting accuracy. In the proposed architecture, retailers make their integrated forecasts and save the results in the supply chain database, and the vendors retrieve the forecasts and make their business plans with retailers. Retailers employ the integrated forecasting technology to unearth potential customers is the major difference from current Web-based DSS. It is expected that potential customer forecasting contribute to the direction of strategy for decision makers, and promote forecasting performance.

Figure 2 Activities in the CPFR process

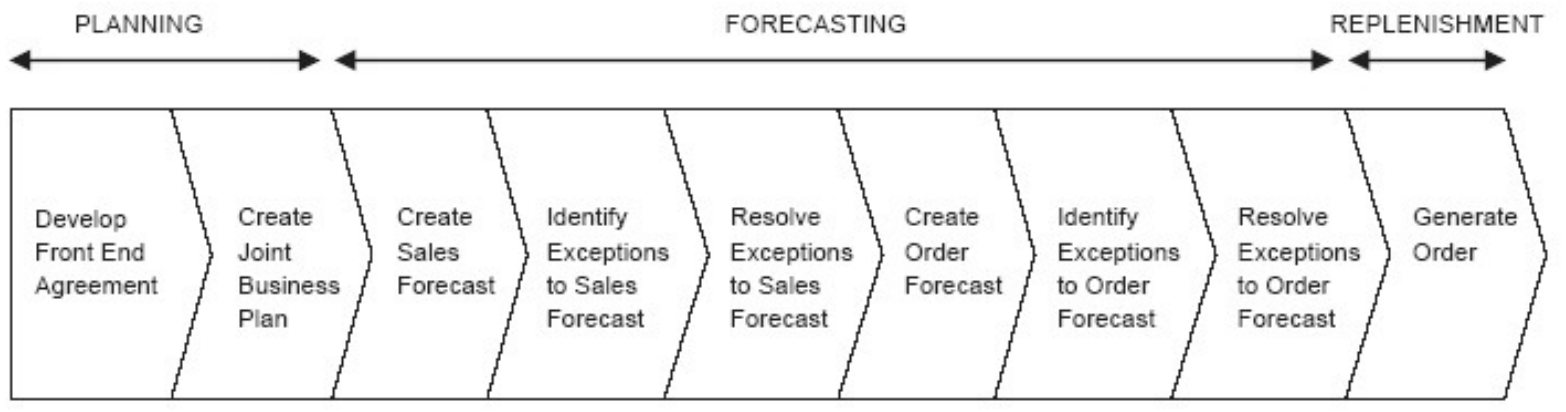


Figure 3 The collaborative forecasting in the e-supply chain portal of U.S. Department of Defense

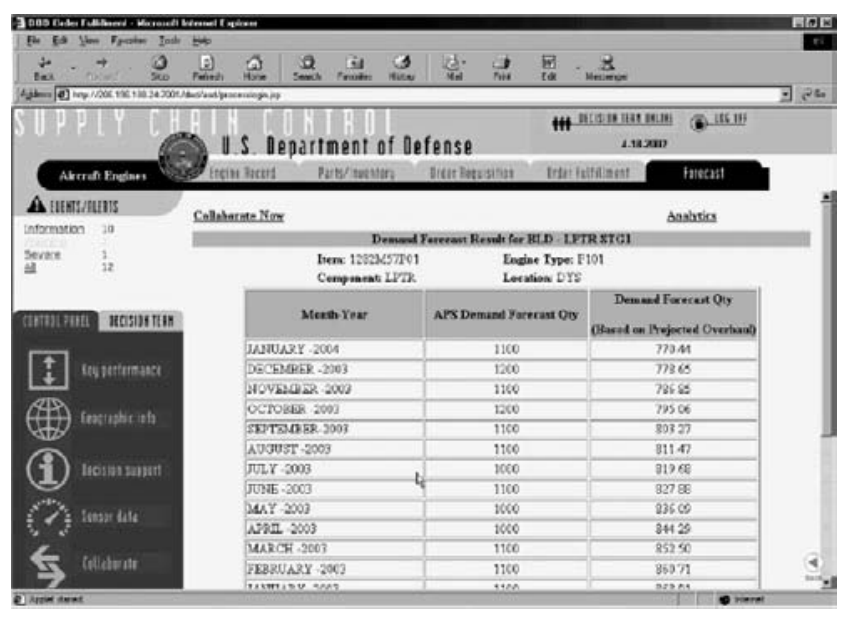

\subsection{Forecasting}

Current forecasting technologies refer to quantitative and qualitative methods. Quantitative methods employ various equation models such as time-series forecasting, brand choice models, data mining, etc. Among them, time-series forecasting methods are used to analyze time-dependent series data and predict the future values; brand choice models are used to calculate the probability of choice to predict choice behavior, and predictive data mining technology is used to produce the model of the system described by the given data, so that a new data can be predicted by the model. Qualitative forecasting technology can be described by

Figure 4 Models Used for VMI DSS

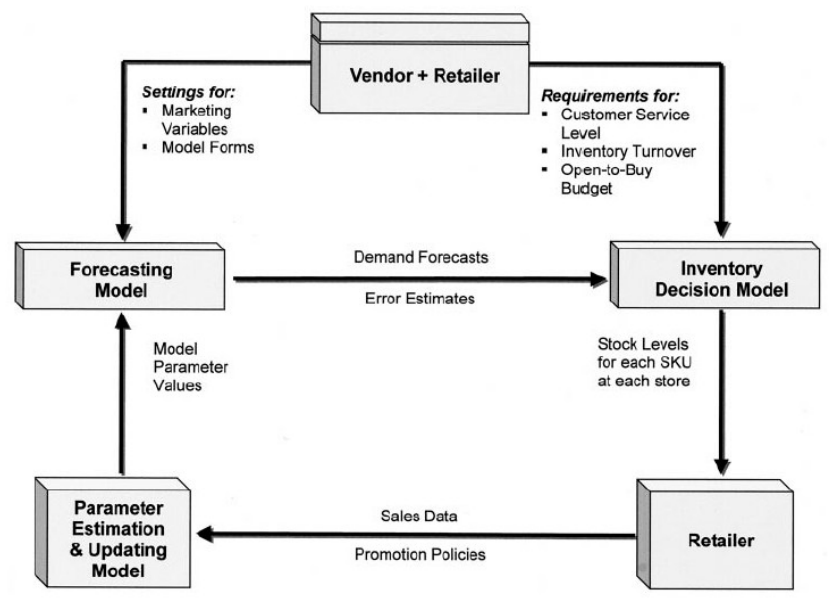

environment scanning, scenarios, and Delphi. A review of recent advances in technological forecasting can be found in Martino (2003). The forecasting technologies in the presented architecture focus on quantitative methods.

Time-series forecasting models are established for describing some time-dependent phenomenon and predicting the future values along the developing trajectory of that phenomenon. Deterministic time-series models assume that the value of time-dependent quantity can be calculated exactly at any instant of time. However, no phenomenon in real world is totally deterministic. The trajectory is influenced by seasonal, trend, cyclical and irregular factors, which make deterministic prediction impossible. In this case, stochastic models can be used to calculate the probability of a future value lying between two specified limits. Described below are typical timeseries stochastic models including moving average, exponential smoothing, and ARIMA.

\subsubsection{Moving Average}

The simple moving average method takes the average value of recent $\mathrm{N}$-period observations as the forecast. The drawback of this method is that equal weight is given to the recent $\mathrm{N}$-period historical data with no weight to data prior to that at all. (Silver \& Peterson, 1985, pp. 104)

\subsubsection{Exponential Smoothing}

Exponential smoothing is a forecasting method that is most effective when the components (trend and seasonal factors) of the time series may be changing over time. It weighs the observed time series values unequally, in which more recent observations are weighed more heavily than more remote observations. For short-term forecasting, it is appropriate for analyzing time-series data according to its demand pattern (Silver \& Peterson, 1985, pp. 102-126)

\subsubsection{Autoregressive Integrated Moving Average (ARIMA)}

In statistics, an autoregressive integrated moving average (ARIMA) model, which is presented by Box, Jenkins, \& Reinsel in 1976, is a generalisation of an autoregressive moving average or (ARMA) model. These models are fitted to time series data either to better understand the data or to predict future points in the series. The model is generally referred to as 
an ARIMA (p,d,q) model where $\mathrm{p}, \mathrm{d}$, and $\mathrm{q}$ are integers greater than or equal to zero and refer to the order of the autoregressive, integrated, and moving average parts of the model respectively (Mills, 1990).

Among the described models, ARIMA yields minimal mean square error (Box et al., 1994), this makes it the typical method for time-series forecasting. In using time-series forecasting methods, forecasters assume that the past of a time series contains all the information needed to predict the future of that time series. An appropriate model is then fitted to the historical data, and the projection of that model becomes the forecast. This assumption implies the neglect of exploring the influences from environmental changes and customer purchase preference, which induces a lagging forecast with unconquerable residual error. Another limitation of time-series forecasting technology is that when it performs on nonlinear time series, the error caused by unknown factors remains to be solved. Recent researchers on time-series forecasting try to help solve this problem by employing heuristic methods such as data mining to capture the demand patterns inherent in nonlinear time series (Ghiassi, Saidane, \& Zimbra, 2005; Peng, Zhang, \& Tian, 2003; Last, Klein, \& Kandel, 2001; Jeong, Jung, \& Park, 2002; Wang \& Wang, 2002). A survey of time-series data mining was presented by Keogh \& Kasetty (2002).

Although some accomplishment have been achieved based on case data, in general difficulties still remain because uncertain demand variation does not follow the same pattern all the time due to consumer behavior, new technologies or products, economic prosperity, and other environmental factors. Exploring the composite effect of these factors that influences customer demand may capture the future trend and help reduce the error existing in classical time-series forecasting models.

\subsection{Segmentation with Data Mining}

Classical segmentation methods refer to qualitative approach such as Recency, Frequency, and Monetary (RFM) analysis, or quantitative approach such as Kmeans. Recent years data mining has received more attention from researchers who work on segmentation. Some of them employ multi-stage procedure by integrating classical segmentation methods with data mining technology, while others take one of the data mining methods as the major approach. The methods used in the literatures referring to implementation of data mining on segmentation are summarized in Table 1.

The ability of learning the relationships between data by self-organizing makes Self-organizing Map (SOM) a popular method to work on clustering analysis. Some researchers employ multi-stage approaches with classical segmentation method such as RFM analysis or K-means, and data mining method such as SOM. They claim that the multi-stage approaches perform over classical methods. Among these researches, extracting customer's RFM values at the first stage, and feeding the RFM values into SOM as input values at the second stage is prevalent. SOM takes these values and learns the relationships between them, and then discriminates the clusters (Ha et al., 2002; Hsieh, 2004; Lingras et al., 2005).

The Apriori algorithm, a well-known data mining technology for association analysis, is also employed in these researches to learn the association rules of demand data. The loyal customer characteristics can be extracted by the Apriori algorithm to construct loyal customer knowledge base. The outside consumers and switchers are matched with the knowledge base to sieve out possible loyal customer candidates, or, to form the Potential Customer Segment.

Table 1

Methods of Data Mining Applications on Segmentation in Literature

\begin{tabular}{|c|c|c|c|}
\hline \multirow{2}{*}{ Single-stage } & \multicolumn{2}{|l|}{ Multi-stage } & \multirow[b]{2}{*}{ Stage III } \\
\hline & Stage I & Stage II & \\
\hline $\begin{array}{l}\text { Ant K-means } \\
\text { (Kuo, Wang, Hu, } \\
\text { \& Chou, 2005) }\end{array}$ & RFM analysis & $\begin{array}{l}\text { SOM (Ha, Bae \& } \\
\text { Park, 2002) }\end{array}$ & \\
\hline $\begin{array}{l}\text { Association } \\
\text { analysis(Liao \& } \\
\text { Chen, 2004) }\end{array}$ & RFM analysis & SOM & $\begin{array}{l}\text { Association } \\
\text { analysis(Hsieh, } \\
\text { 2004) }\end{array}$ \\
\hline \multirow[t]{3}{*}{$\begin{array}{l}\text { SOM (Lingras, } \\
\text { Hogo, Snorek, \& } \\
\text { West, 2005) }\end{array}$} & $\begin{array}{l}\text { LTV (Life Time } \\
\text { Value) }\end{array}$ & $\begin{array}{l}\text { Decision tree, } \\
\text { Logistic } \\
\text { Regression,SOM } \\
\text { (Hwang, Jung, \& } \\
\text { Suh, 2004) }\end{array}$ & $\begin{array}{l}\text { Association } \\
\text { analysis(Hsieh, } \\
\text { 2004) }\end{array}$ \\
\hline & DEA & SOM & $\begin{array}{l}\text { Decision tree(Lee } \\
\& \text { Park, 2005) }\end{array}$ \\
\hline & $\begin{array}{l}\text { MCFA (Multi-group } \\
\text { Confirmatory } \\
\text { Factor Analysis) }\end{array}$ & $\begin{array}{l}\text { SOM (Lee et al., } \\
\text { 2004) }\end{array}$ & \\
\hline
\end{tabular}

\footnotetext{
* Source: the author
} 


\subsection{Brand Choice Models}

A brand choice model represents the underlying process by which an individual consumer integrates information to select a brand from a set of competing brands. Consumers are exposed to various factors that influence their expectations on products. Lattin \& Bucklin (1989) studied the preference effects of price and promotion on brand choice behavior, and proposed a Logit model of consumer response incorporating these factors. They contended in their conclusion that consumers form expectations based on their exposure to promotional activity and that those expectations influence the patterns of brand choice. For this reason, Logit models have long been the benchmark methods of studying consumers' brand choice behavior.

Manrai (1995) reviewed the developments of brand choice models, and provided the survey. In his survey, the choice models are broadly categorized to three groups: (1) multi-attribute choice models, (2) preference and choice mapping models, and (3) conjoint analysis. The multiattribute choice models are the major methods for determination of market structure, demand forecasting, product positioning, buyer segmentation, and prediction of consumer choice. There are two fundamental ways of classifying the multi-attribute choice models, which are driven by two different principles, namely, (1) the principle of utility maximization founded in economic theory (also called "brand-based processing"), and (2) the psychological principle of feature- or attribute-based sequential elimination or "attribute-based processing". Maximum of utilities model assumes that customers select only the product from which they expect to gain the maximum utility value and they reject all the rest. Under this assumption, the utilities are estimated by maximum likelihood estimation method, the calculation of skewness and kurtosis is based on these utilities, and the selection of brand choice models is decided by the skewness and kurtosis rules in knowledge base. A study on selecting an appropriate choice model is presented by Matsatsinis and Samaras (2000). The estimation of purchase tendency in Potential Customer Segment in subsection 4.2.2 is based on their approach.

\section{The Demand Planning DSS Architecture}

The illustration in this section is based on the assumption that the demand is assumed consumer goods demand in retailing industry, while the forecast works on one specific product. Figure 5 depicts the components in the presented architecture. Three of them are directly linked to user interface: Demand Update Interface, Panel Function, and Knowledge Base Interface. Behind Panel Function is Demand Agent, which drives the main process of this DSS architecture. The major effort of this study focuses on Segmentation Module and Forecasting Module, which are the main body of the Panel Function. Below illustrates each component in this architecture.

\subsection{Demand Update Interface}

The main input for DSS is customer demand. Users input demand data through this interface, while Demand Agent reads demand data from it when necessary. Demand Update Interface contains DBMS module, dealing with maintenance of SCM database, data cleaning, data preparation, and information security.

\subsection{Demand Agent}

Demand Agent is the core of the presented DSS architecture. It controls Panel Function, Inference Engine, and Model Base. By the request of Panel Function, Demand Agent reads the request profile and demand data, and inactivates Inference Engine. Inference Engine sends the profile and demand data to Knowledge Base Interface to find a match. If a match is found, then the result is returned and a report is sent back to the user by Demand Agent. If not, Panel Function activates a corresponding module for the request profile. Details are described as below.

\subsubsection{Panel Function}

Panel Function provides the request interface for user. When a request is proposed, Panel Function sends the request profile to Demand Agent. If a match is not found in the knowledge base, Panel Function activates the corresponding module in Panel Function. Section 4 depicts the details of Panel Function. 
Figure 5 Web-based Architecture for Demand Planning

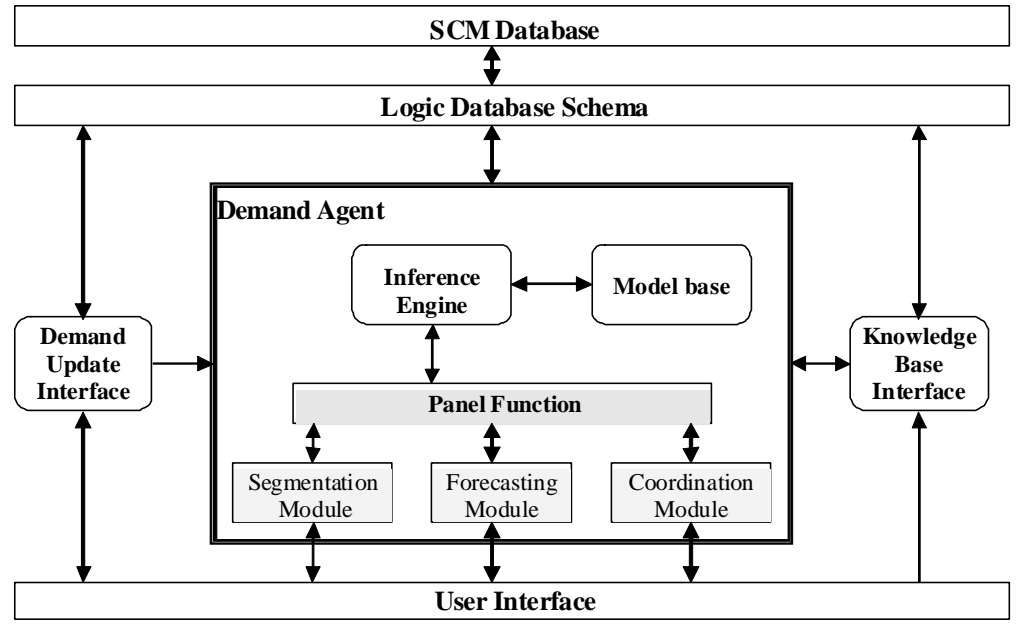

\subsubsection{Inference Engine}

The major mission of Inference Engine involves matching the request profile with knowledge base, and selecting an appropriate model in Model Base in response to the requirement by the running module. Inference Engine also makes judgment on which of the models to be chosen by request, and sends it to the client module.

\subsubsection{Model Base}

Model base contains models and algorithms referring to the state of the art technology. These models and algorithms are grouped as modules, and each module in them will be updated when an improved version is released.

\subsection{Knowledge Base Interface}

Knowledge base consists of fact base and rule base. Fact base stores situations and variables, while rule base stores objectives and criteria (e.g. "what-if" rule). Knowledge Base Interface takes charge of the maintenance of knowledge base. The loyal customer characteristic rules are stored in knowledge base.

\section{The Architecture of Panel Function}

Panel Function consists of Segmentation Module, Forecasting Module, and Coordination Module. As shown in Figure 6, the context starts from Segmentation Module, goes on Forecasting Module, and then terminates at Coordination Module.

\subsection{Segmentation Module}

The major responsibility of Segmentation Module is to separate customers into Loyal Customer Segment, Potential Customer Segment, and Switcher Segment. As depicted in Figure 7, data preparation investigates outliers and work on factor analysis. K-means or RFM ensues for forming primary clusters according to the chosen factors. SOM takes the clusters and learns the relationship in demand data, and generates Loyal Customer Segment and Original Switcher Segment. The Apriori algorithm mines the loyal customer rules, which serve as the sieve for constructing Potential Customer Segment and final Switcher Segment.

\subsection{Forecasting Module}

Customers in the three segments obtained in Segmentation Module reveal different purchase behaviors, therefore different forecasting methods are applied to each segment based on the behavior pattern. An appropriate forecasting tool in each segment is selected with cautious estimation, and the reason of selection is explained in the following subsections respectively. Loyal Customer Segment uses an ARIMA model for its stationary characteristics, while Switcher Segment employs a Bayesian model for calculating each switcher's purchase probability at every promotional activity, and estimating the purchase quantity. The unknown preferences and behaviors of potential customers call for questionnaire analysis and brand choice models 
Figure 6 Architecture of Panel Function

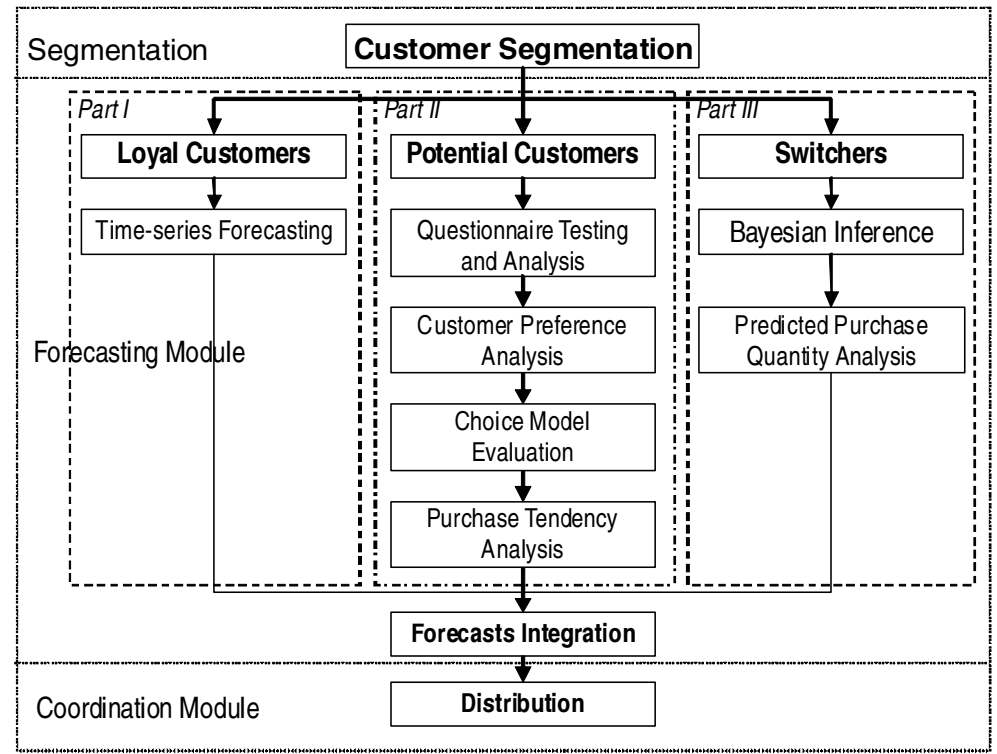

to obtain the purchase tendency, which is the key factor of integration function. The integration function aims at synthesizing the analytical results from the three segments from Segmentation Module.

\subsubsection{Loyal Customer Segment}

Loyal customers are defined to be those who constantly purchase this product. Their purchase behavior is stable, long-term and predictable, which satisfies the stationary requirement of time-series models. According to Box's (1994) conclusion, ARIMA yields minimal mean square error among traditional time-series models, an ARIMA model which fits the demand pattern is selected to predict loyal customer demand. The outcome of the forecasting is $F L_{t^{\prime}}$ which means the forecast value at time period $t$ for loyal customers.

\subsubsection{Potential Customer Segment}

One important objective of this paper is to dig out what is in customer's mind, make more accurate forecasts, and provide decision makers a direction of strategies. The potential customer forecasting is an undeveloped filed, lots of methods may be experimented for this purpose. In this paper, the process of mining purchase tendency includes two stages: questionnaire analysis for mining customer preferences, and quantification of these preferences with brand choice models. Since the preferences and purchase behaviors of customers in this segment are unknown, questionnaire analysis is needed to assist identifying the customer preferences. The result of preference analysis decides what attributes to be used for estimation of utility. With selected factors, the process goes on assessment of the appropriate utility function and calculation of utilities. The utilities are the foundation of estimating skewness and kurtosis, which decide the selection of a fitting choice model. The probability obtained from the selected choice model is the purchase tendency, named $T_{p}$. This estimation process is based on the approach presented by Matsatsinis and Samaras (2000), the following example is provided by Wang \& Yeh (2008) to illustrate the estimation process.

Assume customer A and customer B evaluate 11 competing products with 5 attributes $\left(g_{1}\right.$ to $\left.g_{5}\right)$, and generate their preference tables as shown in Table 2.

The utility values of these attributes in Table 2 are estimated by the following utility functions:

$$
\begin{array}{r}
u_{a j}(g)=0.027 \times \frac{\ln \left(1+g_{1 j}\right)}{\ln (1+5)}+0.361 \times \frac{\ln \left(1+g_{2 j}\right)}{\ln (1+5)}+0.244 \times \frac{\ln \left(1+g_{3 j}\right)}{\ln (1+5)} \\
+0.286 \times \frac{\ln \left(1+g_{4 j}\right)}{\ln (1+5)}+0.082 \times \frac{\max \left(g_{5}\right)+1-g_{5 j}}{\max \left(g_{5}\right)+1}
\end{array}
$$


Figure 7 Process of Segmentation

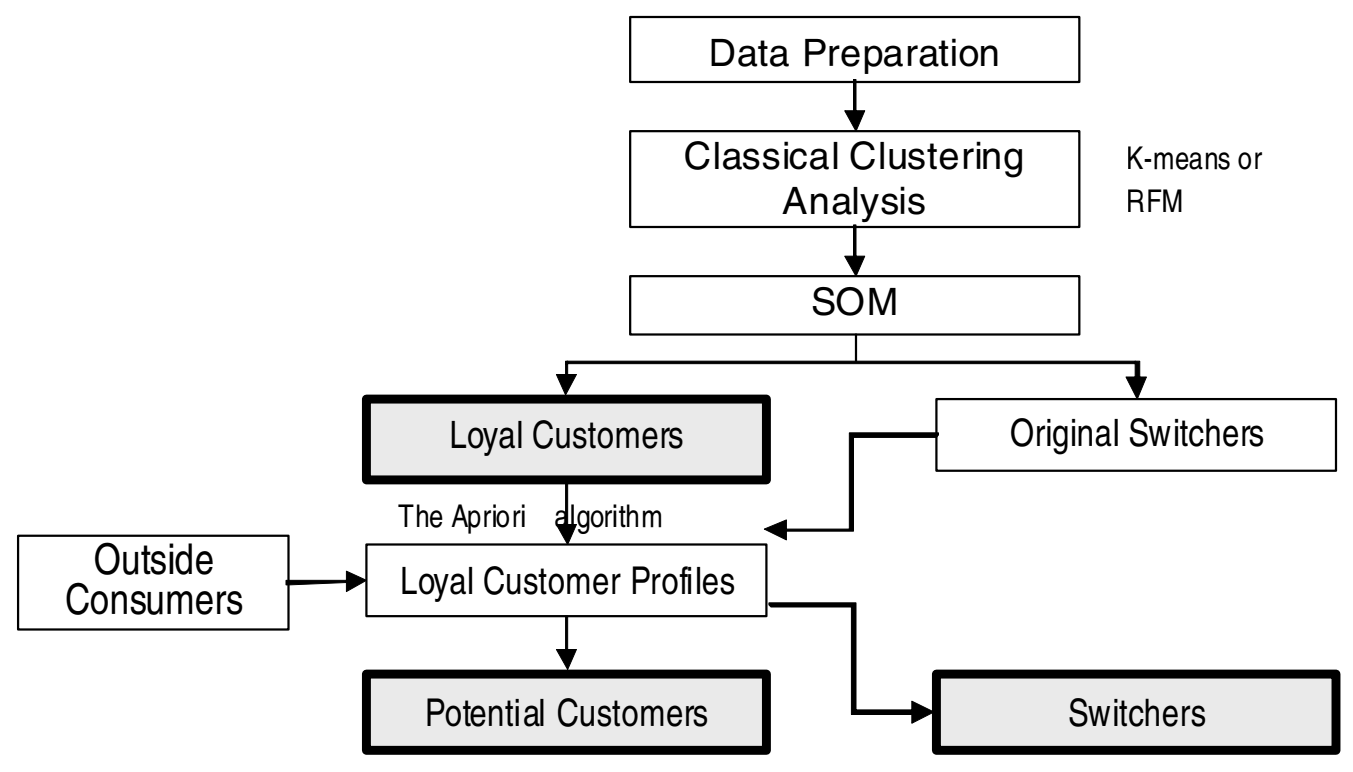

$u_{b j}(g)=0.13 \times \frac{\ln \left(1+g_{1 j}\right)}{\ln (1+5)}+0.045 \times \frac{\ln \left(1+g_{2 j}\right)}{\ln (1+5)}+0.068 \times \frac{\ln \left(1+g_{3 j}\right)}{\ln (1+5)}$

$$
+0.669 \times \frac{\ln \left(1+g_{4 j}\right)}{\ln (1+5)}+0.089 \times \frac{\max _{i}\left(g_{5}\right)+1-g_{5 j}}{\max _{i}\left(g_{5}\right)+1}
$$

The estimated utility values are sorted and divided into several intervals, as shown in Figure 8.

Table 2 Preference Tables and Utilities of Customer A and B

\begin{tabular}{lcccccc}
\hline Customer A & $\mathrm{g}_{1}$ & $\mathrm{~g}_{2}$ & $\mathrm{~g}_{3}$ & $\mathbf{g}_{4}$ & $\mathrm{~g}_{5}$ & Utility \\
\hline Product A & 2 & 1 & 2 & 1 & 20 & 0.4739 \\
Product B & 1 & 2 & 3 & 2 & 31 & 0.6394 \\
Product C & 1 & 1 & 1 & 1 & 65 & 0.3563 \\
Product D & 1 & 1 & 2 & 2 & 48 & 0.4974 \\
Product E & 1 & 1 & 3 & 1 & 37 & 0.4857 \\
Product F & 1 & 2 & 1 & 2 & 18 & 0.5610 \\
Product G & 1 & 1 & 2 & 1 & 53 & 0.4265 \\
Product H & 1 & 1 & 2 & 1 & 64 & 0.4128 \\
Product I & 1 & 1 & 2 & 1 & 55 & 0.4240 \\
Product J & 1 & 1 & 2 & 1 & 35 & 0.4490 \\
Product K & 1 & 1 & 3 & 2 & 58 & 0.5242 \\
\hline
\end{tabular}

The utility values in each interval are used to assess parameters skewness $\alpha_{3}$, kurtosis $\alpha_{4}$ and the judgment of $\delta$. By definition, $\alpha_{3}=m_{3} / \sqrt{m_{2}^{3}}$ and, $\alpha_{4}=\left(m_{4} / m_{2}^{2}\right)-3$ where $m_{r}=\frac{\sum_{i-1}^{n-1} f_{i}\left(x_{i}-\mu\right)^{r}}{\sum_{i=1}^{n-1} f_{i}}$ and, $\mu=\frac{\sum_{i=1}^{n-1} f_{i} x_{i}}{\sum_{i=1}^{n-1} f_{i}}$ $\mu$ is the mean value of the frequencies of arrival, and $f_{i}=n_{i} / n$ is the frequency of arrivals in interval $X_{i}$.

\begin{tabular}{lcccccl}
\hline Customer B & $\mathbf{g}_{1}$ & $\mathbf{g}_{2}$ & $\mathrm{~g}_{3}$ & $\mathrm{~g}_{4}$ & $\mathrm{~g}_{5}$ & Utility \\
\hline roduct A & 5 & 3 & 2 & 2 & 20 & 0.8502 \\
Product B & 3 & 2 & 1 & 2 & 31 & 0.8409 \\
Product C & 5 & 3 & 5 & 4 & 65 & 0.5051 \\
Product D & 3 & 4 & 2 & 1 & 48 & 0.5575 \\
Product E & 4 & 2 & 2 & 3 & 37 & 0.8572 \\
Product F & 4 & 1 & 2 & 4 & 18 & 0.8109 \\
Product G & 1 & 5 & 2 & 3 & 53 & 0.5608 \\
Product H & 5 & 1 & 5 & 3 & 64 & 0.3552 \\
Product I & 2 & 1 & 3 & 2 & 55 & 0.8850 \\
Product J & 2 & 4 & 1 & 5 & 35 & 0.6131 \\
Product K & 2 & 2 & 3 & 2 & 58 & 0.5612 \\
\hline
\end{tabular}


Figure 8 Line Chart of the Sorted Utilities from Customer A and B
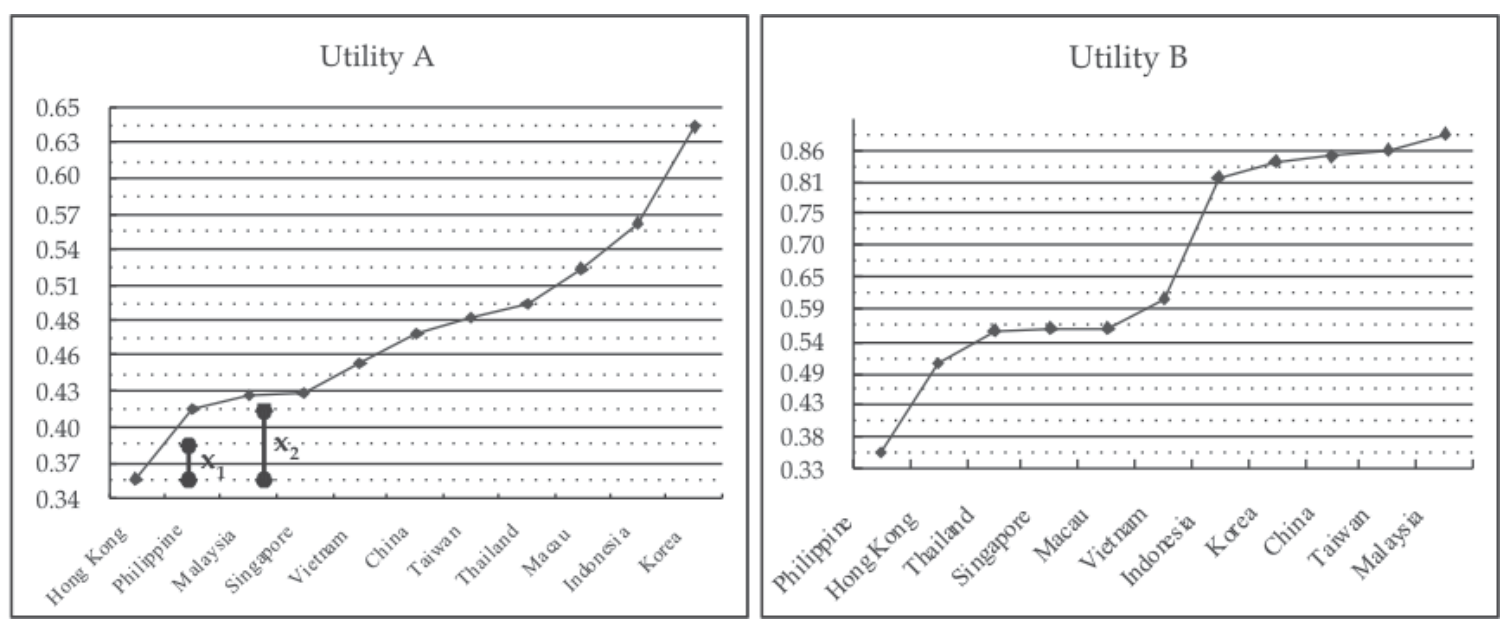

The value of $\delta$ is determined by the range $\mathrm{R}=\mathrm{U}_{\max }-\mathrm{U}_{\min }$ as follows: $\delta=1$ if $0 \leq R \leq 0.1 ; \delta=2$ if $0.1<R \leq 0.3, \delta=3$ if $0.3<R \leq 0.6$, and $\delta=4$ if $0.6<R \leq 1$. Table 3 shows the variables of estimation of $\alpha_{3}$ and $\alpha_{4}$.

A choice model is then selected from Table 4 as a result of mapping the parameters with the knowledge rules in Appendix A (revised from Matsatsinis \& Samaras, 2000).

The choice probability is calculated from the selected choice model. When the probabilities for all destinations come out, the averaged probability for a specific destination is calculated to be the parameter of estimating the number of potential

customers in integration function. Table 5 lists the obtained parameters, the selected choice model, the probabilities for each customer, and the averaged choice probability.

The averaged probability, or the purchase tendency, is the base of transformation function in integration process.

\subsubsection{Switcher Segment}

The definition of switchers refers to the customers who only buy the specific product at promotional activities or premium price, which usually happen on holidays or celebrations. This purchase behavior

Table 3 Necessary Parameters for Assessing Skewness and Kurtosis Coefficients

\begin{tabular}{|c|c|c|c|c|c|c|c|c|c|c|}
\hline & $\mathrm{U}_{\max }$ & $U_{\min }$ & $\mathbf{R}$ & $\delta$ & $\mathrm{m}_{2}$ & $\mathrm{~m}_{3}$ & $\mathrm{~m}_{4}$ & $\mu$ & & \\
\hline$A$ & 0.6394 & 0.3563 & 0.2831 & 2 & 0.0046 & 0.0002 & 0.0001 & 0.5068 & & \\
\hline \multirow[t]{2}{*}{ B } & 0.8850 & 0.3552 & 0.5299 & 3 & 0.0303 & -0.0003 & 0.0013 & 0.7188 & & \\
\hline & $x_{1}$ & $x_{2}$ & $x_{3}$ & $x_{4}$ & $X_{5}$ & $X_{6}$ & $x_{7}$ & $X_{8}$ & $X_{9}$ & $X_{10}$ \\
\hline A & 0.3987 & 0.4271 & 0.4554 & 0.4837 & 0.5120 & 0.5403 & 0.5686 & 0.5969 & 0.6252 & 0.6536 \\
\hline \multirow[t]{2}{*}{ B } & 0.4346 & 0.4876 & 0.5406 & 0.5936 & 0.6466 & 0.6996 & 0.7526 & 0.8056 & 0.8585 & 0.9115 \\
\hline & $f_{1}$ & $f_{2}$ & $f_{3}$ & $f_{4}$ & $f_{5}$ & $f_{6}$ & $f_{7}$ & $f_{8}$ & $f_{9}$ & $f_{10}$ \\
\hline A & 0.0909 & 0.0000 & 0.2727 & 0.0909 & 0.2727 & 0.0909 & 0.0000 & 0.0909 & 0.0000 & 0.0909 \\
\hline B & 0.0909 & 0.0000 & 0.0909 & 0.2727 & 0.0909 & 0.0000 & 0.0000 & 0.0000 & 0.0909 & 0.3636 \\
\hline
\end{tabular}


1. Luce

$$
P_{i j}(C)=\frac{U_{i j}}{\sum_{k \in C} U_{i k}}
$$

2. Lesourne

$$
P_{i j}(C)=\frac{U_{i j}^{2}}{\sum_{k \in C} U_{i k}^{2}}
$$

3. Multinomial Logit Model (McFadden-1)

$$
P_{i j}(C)=\frac{e^{U_{i j}}}{\sum_{k \in C} e^{U_{i k}}}
$$

4. Slightly reinforced (McFadden-2)

$$
P_{i j}(C)=\frac{e^{2 U_{i j}}}{\sum_{k \in C} e^{2 U_{i k}}}
$$

5. Width of Utilities-1

$$
P_{i j}(C)=\frac{U_{i j}^{U_{\max }-U_{\min }}}{\sum_{k \in C} U_{i k}^{U_{\max }-U_{\min }}}
$$

6. Width of Utilities-2

$$
P_{i j}(C)=\frac{e^{\left(U_{\max }-U_{\min } \mid U_{i j}\right.}}{\sum_{k \in C} e^{\left(U_{\max }-U_{\min } \mid U_{i k}\right.}}
$$

7. Maximum of Utilities

$$
P_{i j}(j \mid C)=\left\{\begin{array}{ll}
\frac{1}{m} & \text { if } U_{\max } \geq U_{j} \geq U_{\max }-\varepsilon_{i}, \\
0 & \text { otherwise }
\end{array} \text { where } \quad \varepsilon_{i}=\frac{U_{\max }-U_{\min }}{n-1}\right.
$$

8. Equal Probabilities

$$
P_{j}=\frac{1}{m} \text {, where } U_{\max }-U_{\min } \leq 0.1
$$

* Source: Matsatsinis and Samaras (2000).

reveals event-driven pattern, and a priori probability may be obtained from historical data, so Bayesian inference method is employed to calculate the conditional probability of customer's decision in this paper. Brand choice models may also be considered as the analysis tool, but they do not include historical data, the information from historical data would be lost.

Table 5 Parameters, selected choice models, and averaged choice probability

\begin{tabular}{ccccccc}
\hline & $\delta$ & $\alpha_{3}$ & $\alpha_{4}$ & Model & Probability & Average \\
\hline A & 2 & 0.6453 & -0.0903 & 3 & 0.0925 & 0.0929 \\
B & 3 & -0.0613 & -1.5907 & 3 & 0.0933 & \\
\hline
\end{tabular}

The outcome of the Bayesian model is a probability, and a total purchase quantity is estimated. The estimated total quantity is then multiplied by the probability to obtain the Switcher forecast at time period $t$, named $F S_{t}$. An important mission of Bayesian inference is to induce a more accurate aggregate forecast other than a single-series one. The evaluation of forecasting performance in this segment consists of the aggregation of Loyal Customer Segment and Switcher Segment.

\subsubsection{Integration Function of Forecasting}

One of the major contributions of this study is the integration function $F_{t^{\prime}}$, which integrates the demand forecasts $F L_{t^{\prime}} T_{p^{\prime}}$ and $F S_{t} . F L_{t}$ and $F S_{t}$ are additive quantities, while $T_{p}$ is a probability representing 
a tendency. This calls for a transformation function $g\left(T_{p}\right)$, which is formulated depending on the distribution of the demand data, for transforming the tendency to the corresponding quantity. Below lists the general form of integration function.

$F_{t}=f\left(F L_{t}, T_{p}, F S_{t}\right)=F L_{t}+g\left(T_{p}\right)+F S_{t}$

$F_{t}$ is the ultimate decision mechanism of the integrated forecast, and transformation function $g\left(T_{p}\right)$ is the key function. Given a known demand distribution, $g\left(T_{p}\right)$ is the expected quantity of the distribution. If the demand distribution is unknown, is estimated with an appropriate method. For example, an averaged quantity of loyal customer segment may serve as the base of potential customer, and the multiplication of the base and the purchase tendency constructs the result of $g\left(T_{p}\right)$.

\section{Implication of the Proposed Architecture}

In the proposed architecture, customers are divided into three different groups: Loyal Customer Segment, Potential Customer Segment, and Switcher Segment. ARIMA models are applied to Loyal Customer Segment for estimating a timeseries forecast, questionnaire and brand choice models are performed in Potential Customer Segment to obtain customer purchase tendency, and Bayesian inference is employed in Switcher Segment to evaluate the purchase quantities at promotional activities. The integration function integrates these analytical results to obtain an integrated forecast, which is anticipated to mitigate the forecasting error.

This section discusses the implication of the presented architecture. As depicted in Figure 5, the presented architecture provides a web mechanism for collaboration between supply chain members, it involves internet information technology. This study emphasizes on the forecasting core, namely Panel Function. Among the modules in Panel Function, Forecasting Module is the core of this study. Subsection 5.1 to subsection 5.5 discusses the implication of each component of the forecasting core.

\subsection{Segmentation}

Segmentation is the important foundation of Panel Function. Customers are clustered in accordance with their behaviors, and are analyzed by different technologies corresponding to their demand characteristics. This means the heterogeneity in demand data is distinguished into different groups, in each group a fitting model is employed, and the total forecasting error is alleviated expectantly.

\subsection{Loyal Customer Forecasting}

Loyal customers are defined those who constantly purchase the same product, their demand data reveals stationary pattern. ARIMA performs excellently on linear, stationary time series, so ARIMA is used as the forecasting model in Loyal Customer Segment. The classical model contributes to steady part substantially in this study.

\subsection{Potential Customer Forecasting}

Potential customer forecasting is unique for its feature of mining. The definition of potential customer is the possible customers who never purchase the specific product, but possess similar characteristic with loyal customers. For digging out the possible customers, a well-designed questionnaire is needed to quantify the preference inside customers' mind. The outcome of questionnaire analysis is a preference table, and the estimation of utility function is based on this table. The utility function induces utility values for all competing brands. The utility values constitute the foundation of selecting an appropriate choice model, which estimates the customer purchase tendency. An important implication of this purchase tendency is that it indicates a trend of customer preference, which provides a leading view of demand planning. This is the major difference of this presented forecasting method from traditional forecasting models.

\subsection{Switcher Forecasting}

Switchers purchase only at promotional activities or premium prices, making the switcher demand a nonstationary series, which explains part of the forecasting error. Bayesian inference is selected as the alternative solution to capture the purchase probability, and to estimate the purchase quantity due to the event-driven pattern. This estimated quantity helps mitigate the forecasting error by aggregating itself with the results 
from the other two segments, instead of stand-alone forecast.

\subsection{Integration Function}

The Forecasting Module presented in this study starts from the end of Segmentation Module, through different analysis and forecasting processes in each segment, and ends up at integration function, which integrates the analytical results from the three segments. The anticipated contribution of integration function is a more accurate forecast to promote demand planning performance. The implication of this result points out a different direction from traditional linear forecasting approaches: differentiation of analysis and forecasting in different customer segments is in anticipation of working effectively on promoting demand forecasting accuracy. Furthermore, the influence from qualitative factors such as customer purchase tendency should be dug out and accommodated in the forecasting model to reduce the unpredictable error.

\subsection{Research Limitations}

Due to the difficulty of obtaining customer demographics and actual sales data, the implementation of the presented forecasting core is restricted to whether customer demographics are available. A technological limitation is that the implementation of the presented Web-based DSS might take years of expert teamwork effort.

\section{Conclusion and Future Research}

Demand planning is the key factor of lowering down inventory level and gaining maximum profit in SCM. In the past, time-series forecasting models, the classical methods for demand forecasting, assume time series as a linear series containing all the information needed to forecast the future, and this makes a problem when they are applied to a nonlinear series. Forecasting Module, the core of this architecture, is designed to work out this problem by mining customer purchase tendency with their preference.

At the beginning of this study, the problem of demand planning in SCM is stated. Ineffective demand planning leads to serious problems such as the bullwhip effect and severe inventory problems, a Web-based DSS architecture is proposed in this study for providing more effective and accurate forecasts which may improve the demand planning performance, as well as facilitating collaborative forecasting in a supply chain with efficient collaboration mechanism. The proposed Web-based DSS architecture is designed to help unloose the obstruction of information caused by information sharing deficiencies. This architecture is quite complicated but worth implementation for its effectiveness, it facilitates collaborative forecasting and benefits quick response in a supply chain.

The Web-based DSS architecture proposed in this study is a first stone of integrated forecasting system, pointing out an optimistic direction of improving forecasting technology. Boundless development may be done by future effort in this architecture. Some possible future researches are: (1) applying Fuzzy to seize customer preference in comparison with brand choice models (2) analyzing switchers' choice behavior with brand choice models. This might lead to a deeper behavioral analysis. (3) estimating potential customer base with different approaches and variables. For instance, economic prosperity might be an important index of potential customer base.

It is interesting in a managerial implication, to decipher what influences the decision process behind purchase behavior, and how to measure it. The Potential Customer Forecasting is an attempt to quantify the qualitative inside tendency, and provides it as a foundation of quantitative integration forecasting. Further research toward this direction could make the integrated forecasting technology fruitful.

\section{References}

Achabal, D.D., Mcintyre, S.H., Smith, S.A., and Kalyanam, K. (2000). A Decision Support System for Vendor Managed Inventory, Journal of Retailing, 76(4), pp. 430-454.

Arampatzis, G., Kiranoudis, C.T., Scaloubacas, P., and Assimacopoulos, D. (2004). A GIS-based Decision Support System for Planning Urban Transportation Policies, European Journal of Operational Research, 152(2), pp. 465-475.

Barratt, M., Oliveira, A. (2001). Exploring the Experience of Collaborative Planning Initiatives. Journal of Physical Distribution E Logistics Management, 31(4), pp. 266-289.

Bhargava, H.K., Power, D.J., and Sun, D.W. (2007). Progress I Web-based Decision Support Technologies, Decision Support Systems, 43(4), pp. 1083-1095. 
Biswas, S, and Narahari, Y. (2004). Object Oriented Modeling and Decision Support for Supply Chains, European Journal of Operational Research, 153(3), pp. 704-726.

Blackhurst, J., Wu, T., and O'Grady, P. (2005). PCDM; a Decision Support Modeling Methodology for Supply Chain, Product, and Process Design Decision, Journal of Operations Management, 23(3-4), pp. 325-343.

Box, G.E.P., Jenkins, G.M., and Reinsel, G.C. (1994). Time series analysis: forecasting $\mathcal{E}$ control, Prentice Hall, New Jersey.

Boyson, S., Corsi, T., and Verbraeck, A. (1998). The ESupply Chain Portal: A Core Business Model. Transportation Research, 39E(2), pp. 175-192.

Crum, C., \& Palmatier, G.E. (2004). Demand Collaboration: What's Holding us Back. Supply Chain Management Review, 8(1), pp. 54-61.

Danese, P., Romanob, P. \& Vinelli, A. (2004). Managing business processes across supply networks: the role of coordination mechanisms. Journal of Purchasing and Supply Management, 10(4-5), pp. 165-177.

Fredenhall, L., and Hill, E. (2001). Basics of Supply Chain Management, St. Lucie Press, New York.

Gayialis, S.P., and Tatsiopoulos, I.P. (2004). Design of an IT-driven Decision Support System for Vehicle Routing and Scheduling. European Journal of Operational Research, 152(2), pp. 382-398.

Ghiassi, M., and Spera, C. (2003). Defining the InternetBased Supply Chain System for Mass Customized Markets. Computers E Industrial Engineering, 45(1), pp. 17-41.

Ghiassi, M., Saidane, H., and Zimbra, D.K. (2005). A Dynamic Artificial Neural Network Model for Forecasting Time Series Events. International Journal of Forecasting, 21(2), pp. 341-362.

Gunasekaran, A., and Ngai, E.W.T. (2004). Information Systems in Supply Chain Integration \& Management. European Journal of Operational Research, 159(2), pp. 269-295.

Ha, S.H., Bae, S.M., and Park, S.C. (2002). Customer's Time-variant Purchase Behavior and Corresponding Marketing Strategies: An Online Retailer's Case. Computers $\mathcal{E}$ Industrial Engineering, 43(4), pp. 801-820.

Hsieh, N.C. (2004). An Integrated Data Mining and Behavioral Scoring Model for Analyzing Bank Customers. Expert Systems with Applications, 27(4), pp. 623-633.

Hwang, H.S., Jung. T.S., and Suh, E.H. (2004). A LTV Model and Customer Segmentation Based on Customer Value: A Case Study on the Wireless Telecommunication Industry. Expert Systems with Applications, 26(2), pp. 181-188.

Jeong, B., Jung, H.S., and Park, N.K. (2002). A Computerized Causal Forecasting System Using Genetic Algorithms in Supply Chain Management. The Journal of Systems and Software, 60(3), pp. 223-237.

Keogh, E., and Kasett,y S. (2002). On the need for time series data mining benchmarks: A survey and empirical demonstration, keogh02need.html.

http://citeseer.ist.psu.edu/

Kuo, R.J., Wang, H.S., Hu, T.L., and Chou, S.H. (2005). Application of Ant K-Means on Clustering Analysis. Computers and Mathematics with Applications, 50(1012), pp. 1709-1724.

Last, M., Klein, Y., and Kandel, A. (2001). Knowledge Discovery in Time Series Databases. Proc. of IEEE Transactions on System, Man, and Cybernetics-Part B: Cybernetics, 31(1), pp. 160-169.

Lattin, J.M., and Bucklin, R.E. (1989). Reference Effects of Price and Promotion on Brand Choice Behavior. Journal of Marketing Research, 26, pp. 299-310.

Lee, H.L., Padmanabhan, V., and Whang, S. (1997). The Bullwhip Effect in Supply Chains, Sloan Management Review, 38(3), pp. 93-102.

Lee, J.H., and Park, S.C. (2005). Intelligent Profitable Customers Segmentation System Based on Business Intelligence Tools, Expert Systems with Applications, 29(1), pp. 145-152.

Lee, S.C., Suh, Y.H., Kim, J.K., and Lee, K.J. (2004). A CrossNational Market Segmentation of Online Game Industry Using SOM. Expert Systems with Applications, 27(4), pp. 559-570.

Liao, S.H., and Chen, Y.J. (2004). Mining Customer Knowledge for Electronic Catalog Marketing. Expert Systems with Applications, 27(4), pp. 521-532.

Lingras, P., Hogo, M., Snorek, M., and West, C. (2005). Temporal Analysis of Clusters of Supermarket Customers: Conventional Versus Interval Set Approach. Information Science, 172 (1-2), pp. 215-240.

Machuca, J.A.D., and Barajas, R.P. (2004). The Impact of Electronic Data Interchange on Reducing Bullwhip Effect \& Supply Chain Inventory Costs, Transportation Research, 40E(3), pp. 209-228.

Manrai, A.K. (1995). Mathematical Models of Brand Choice Behavior. European Journal of Operational Research, 82(1), pp. 1-17.

Martino, J.P. (2003). A Review of Selected Recent Advances in Technological Forecasting. Technological Forecasting and Social Change, 70(8), pp. 719-733.

Matsatsinis, N.F., and Samaras, A.P. (2000). Brand Choice Model Selection Based on Consumers' Multicriteria Preferences and Experts' Knowledge. Computers $\mathcal{E}$ Operations Research, 27(7-8), pp. 689-707.

Mills, T.C. (1990). Time Series Techniques for Economists. Cambridge University Press.

Min, H., and Zhou, G. (2002). Supply Chain Modeling: Past, Present, and Future, Computers and Industrial Engineering, 43(1-2), pp. 231-249.

Patterson, K.A., Grimm, C.M., and Corsi, T.M. (2003). Adopting New Technologies for Supply Chain Management. Transportation Research, 39E(2), pp. 95121.

Peng, Y.Q., Zhang, Y., and Tian, H.S. (2003). Research of Time Series Pattern Finding Based on Artificial Neural Network. The Second International Conference on Machine Learning and Cybernetics, Xi'an. 
RÃÃder, A., and Tibken, B. (2006). A Methodology for Modeling Inter-company Supply Chains and for Evaluating a Method of Integrated Product and Process Documentation, European Journal of Operational Research, 169(3), pp. 1010-1019.

Rhee, H., and Bell, D.R. (2002). The Inter-store Mobility of Supermarket Shoppers. Journal of Retailing, 78(4), pp. 225-237.

Seifert, D. (2003). Collaborative Planning, Forecasting, and Replenishment: How to create a Supply Chain Advantage. Amacom: New York.

Shim, J.P., Warkentin, M., Courtney, J.F., Power, D.J., Sharda, R., and Carlsson, C. (2002). Past, Present, and Future of Decision Support Technology. Decision Support Systems, 33(2), pp. 111-126.

Silver, E.A. \& Peterson, R. (1985). Decision System for Inventory Management $\mathcal{E}$ Production Planning. New York, NY: John Wiley \& Sons.
Strader, T.J., Lin, F.R., and Shaw, M.J. (1998). Information Infrastructure for Electronic Virtual Organization Management. Decision Support Systems, 23(1), pp. 7594.

Thomas, J. (1999). Why Your Supply Chain Doesn't Work. Logistics Management and Distribution Report, 38(6), pp. 42-44.

VICS (2000). CPFR Guidelines. Voluntary Inter-industry Commerce Standards, available at http://www.cpfr.org.

Wang, T.Y., and Yeh, D.H. (2008). A Web-Based DSS Architecture and its Forecasting Core in Supply Chain Management, International Journal of Electronic Business Management, (in press).

Wang, X.Y., and Wang, Z.O. (2002). Stock Market Time Series Data Mining Based on Regularized Neural Network and Rough Set, The First International Conference on Machine Learning and Cybernectics, Beijing.

Tien-You Wang is an Associate Professor in the Department of International Business Management at Tainan University of Technology (TUT), Taiwan. She received her Ph.D. degree in Business Administration at National Chung Cheng University in 2006. Her research interests are integrating IT and demand planning related technologies in Supply Chain Management. In particular, she is interested in data mining, neural network, and time series forecasting.

Din-Horng Yeh is an Associate Professor in the Department of Business Administration at National Chung Cheng University (CCU), Taiwan. His research interests are Queuing and Simulation. 


\section{Appendix A The Rule Base of Choice Model Selection}

Notation:

- $\quad \delta, \alpha_{3^{\prime}} \alpha_{4}$ : category of utility, skewness, kurtosis.

- $\quad$ Model: the model number in Table 5.

\section{Rule 1}

if $\delta=1$ then Model $=8$

\section{Rule 2}

if $\delta=2$ and $\left(\alpha_{3} \geqq-0.25\right.$ and $\left.\alpha_{3} \leqq 0.25\right)$ and $\alpha_{4}<-0.5$ then Model $=1$

\section{Rule 3}

if $\delta=2$ and $\left(\alpha_{3} \geqq-0.25\right.$ and $\left.\alpha_{3} \leqq 0.25\right)$ and $\left(\alpha_{4} \geqq-0.5\right.$ and $\left.\alpha_{4} \leqq 0.5\right)$ then Model $=2$

\section{Rule 4}

if $\delta=2$ and $\left(\alpha_{3} \geqq-0.25\right.$ and $\left.\alpha_{3} \leqq 0.25\right)$ and $\alpha_{4}<0.5$ then Model $=3$

\section{Rule 5}

if $\delta=2$ and $\left(\alpha_{3}<0.25\right.$ and $\left.\alpha_{3}<-0.5\right)$ then Model $=2$

\section{Rule 6}

if $\delta=2$ and $\alpha_{3}>0.25$ and $\left(\alpha_{4} \geqq-0.5\right.$ and $\left.\alpha_{4} \leqq 0.5\right)$

then Model $=3$

\section{Rule 7}

if $\delta=2$ and $\alpha_{3}<0.25$ and $\alpha_{4}<0.5$ then

Model $=4$

\section{Rule 8}

if $\delta=2$ and $\alpha_{3}<-0.25$ and $\alpha_{4}<-0.5$ then Model $=3$

\section{Rule 9}

if $\delta=2$ and $\alpha_{3}<-0.25$ and $\left(\alpha_{4} \geqq-0.5\right.$ and

\section{Rule 10}

$\left.\alpha_{4} \leqq 0.5\right)$ then Model $=4$

if $\delta=2$ and $\alpha_{3}<-0.25$ and $\alpha_{4}>0.5$ then Model $=5$

\section{Rule 11}

if $\delta=3$ and $\left(\alpha_{3} \geqq-0.25\right.$ and $\left.\alpha_{3} \leqq 0.25\right)$ and $\alpha_{4}<-0.5$ then Model $=3$

\section{Rule 12}

if $\delta=3$ and $\left(\alpha_{3} \geqq-0.25\right.$ and $\left.\alpha_{3} \leqq 0.25\right)$ and $\left(\alpha_{4} \geqq-0.5\right.$ and $\left.\alpha_{4} \leqq 0.5\right)$ then Model $=4$

\section{Rule 13}

if $\delta=3$ and $\left(\alpha_{3} \geqq-0.25\right.$ and $\left.\leqq 0.25\right)$ and $\alpha_{4}<0.5$ then Model $=5$

\section{Rule 14}

if $\delta=3$ and $\alpha_{3}>0.25$ and $\alpha_{3}<-0.5$ then Model $=2$

\section{Rule 15}

if $\delta=3$ and $\alpha_{3}>0.25$ and $\left(\alpha_{4} \geqq-0.5\right.$ and

$\left.\alpha_{4} \leqq 0.5\right)$ then Model $=3$

\section{Rule 16}

if $\delta=3$ and $\alpha_{3}>0.25$ and $\alpha_{4}>0.5$ then Model $=4$ 


\section{Rule 17}

if $\delta=3$ and $\alpha_{3}<-0.25$ and $\alpha_{4}<-0.5$ then Model $=4$

\section{Rule 19}

if $\delta=3$ and $\alpha_{3}<-0.25$ and $\alpha_{4}>0.5$ then Model $=6$

\section{Rule 18}

if $\delta=3$ and $\alpha_{3}<-0.25$ and $\left(\alpha_{3} \geqq-0.5\right.$ and $\left.\alpha_{4} \leqq 0.5\right)$ then Model $=5$

\section{Rule 21}

if $\delta=4$ and $\left(\alpha_{3} \geqq-0.25\right.$ and $\left.\alpha_{3} \leqq 0.25\right)$ and $\left(\alpha_{4} \geqq-0.5\right.$ and $\left.\alpha_{4} \leqq 0.5\right)$ then Model $=5$

\section{Rule 20}

if $\delta=4$ and $\left(\alpha_{3} \geqq-0.25\right.$ and $\left(\alpha_{3} \leqq 0.25\right)$ and $\left.\alpha_{3} \leqq-0.5\right)$ then Model $=3$

\section{Rule 23}

if $\delta=4$ and $\alpha_{3}<0.25$ and $\alpha_{4}<-0.5$ then Model $=5$

\section{Rule 22}

if $\delta=4$ and $\left(\alpha_{3} \geqq-0.25\right.$ and $\left.\alpha_{3} \leqq 0.25\right)$ and $\alpha_{4}>0.5$ ) then Model $=4$

\section{Rule 25}

if $\delta=4$ and $\alpha_{3}<0.25$ and $\alpha_{4}>0.5$ then Model $=7$

\section{Rule 24}

if $\delta=4$ and $\alpha_{3}>0.25$ and $\left(\alpha_{4} \geqq-0.5\right.$ and $\left.\alpha_{4} \leqq-0.5\right)$ then Model $=6$

\section{Rule 27}

if $\delta=4$ and $\alpha_{3}<-0.25$ and $\left(\alpha_{4} \geqq-0.5\right.$ and $\left.\alpha_{4} \leqq 0.5\right)$ then Model $=7$

\section{Rule 26}

if $\delta=4$ and $\alpha_{3}<-0.25$ and $\alpha_{4}<-0.5$ then

Model $=6$

\section{Rule 28}

if $\delta=4$ and $\alpha_{3}<-0.25$ and $\alpha_{7}>0.5$ then Model $=7$ 